\title{
Investigating the challenges and factors influencing the use of the learning management system during the Covid-19 pandemic in Afghanistan
}

\author{
Mustafa Kamel Mohammadi ${ }^{1}$ (D) Abdul Aziz Mohibbi² ${ }^{2}$ \\ Mohammad Hadi Hedayati ${ }^{3}$
}

Received: 16 December 2020 / Accepted: 22 March 2021 / Published online: 7 April 2021

(c) The Author(s), under exclusive licence to Springer Science+Business Media, LLC, part of Springer Nature 2021

\begin{abstract}
Successful implementation and use of learning management systems (LMSs) have become a critical challenge for many higher education institutes during the Covid19 pandemic. Although LMSs with lots of features were developed for universities, the success of those systems is highly related to a detailed understanding of challenges and factors influencing the use of the systems among their users. HELMS (Higher Education Learning Management System) is a countrywide LMS used for teaching and learning during the quarantine period caused by covid-19 in Afghanistan universities. As it was the first experience of Afghan universities in using the learning management systems during the pandemic, challenges were expected to appear. No previous research has been conducted on either studying the challenges of using the HELMS or investigating the factors influencing the use of HELMS during the Covid-19 pandemic in Afghanistan. Hence, there was no unified view of the potential challenges of using HELMS and factors influencing the use of the HELMS among the researchers. This research aims to investigate the challenges that face the use of HELMS and explore the factors influencing the use of HELMS among both lecturers and students. This study employed a qualitative research method by conducting semi-structured interviews with 100 participants including university management, lecturers, and students. Thematic analysis was used as a method for the analysis of qualitative data. The findings of this research will help policymakers, researchers, and practitioners in public and private universities to grasp knowledge on the successful implementation and use of LMSs during covid-19 and afterward.
\end{abstract}

Keywords E-learning · LMS · Challenges of E-learning · HELMS · Covid-19 . Adoption factors

Mustafa Kamel Mohammadi mustafakamel@bu.edu.af

Extended author information available on the last page of the article 


\section{Introduction}

Information and Communication Technology (ICT) has transformed and reshaped many aspects of modern life. Education and learning have also been affected by ICT through the integration of many technologies used for educational purposes such as computers, the internet, and mobile technologies (Marshall, 2012). E-learning or online learning is said to be the use of any device with internet access to engage in the learning process from anywhere anytime (Dhawan, 2020). Using learning management systems is one approach to online learning (Almaiah et al., 2020). Learning Management Systems (LMSs) have gained popularity among both the educational institutes and students as a software application used for planning, implementing, and examining the whole education process (Jamal \& Shanaah, 2011). LMSs are also popular with the following titles as knowledge management systems, course management software, and virtual educational or learning environments (Al Musawi \& Abdelraheem, 2004). Moodle, Sakai, Blackboard, and ATutor are the well-known LMS software solutions used for online learning. These systems have features including student enrollment, exams, quizzes, assignments, course management, messaging, uploading course material, etc. (Almaiah et al., 2020).

Since March 2020, after the Covid-19 virus turned into a worldwide pandemic (WHO, 2020), many public and private institutes including schools and universities were closed across the countries including Afghanistan. From the beginning of the new academic year of 2020, the education sector in Afghanistan was facing a critical challenge in teaching and learning. Since the start of the educational year in March 2020 at the time of countrywide quarantine, the Ministry of Higher Education (MoHE) forced public universities to deliver the educational material through online platforms. Google classroom, WhatsApp, Facebook, and Telegram were the most commonly used online platforms used for accessing the educational material online (Bamyan University, 2020). In June 2020, the Ministry of Higher education (MoHE) of Afghanistan come up with a countrywide learning management system project called HELMS (Higher Education Learning Management System), which is a web-based service used as a tool that assists universities in managing, delivering, planning, and tracking the learning and teaching process. It was introduced as the primary and the only medium of education during the pandemic proposed by MoHE of Afghanistan to be used by public universities.

As it was the first experience of Afghan universities in using the learning management system during a pandemic, challenges were expected to appear during the use of learning management systems by university management teams, lecturers, and students. To the best of our knowledge, no previous research has been conducted on studying the challenges of using the HELMS from the university management perspective. Besides, no literature has been found investigating the factors influencing the use of HELMS by lecturers and students during the Covid-19 pandemic in Afghanistan universities. It is also worth to be mentioned that previous studies investigated the challenges of using learning management systems as a general term in the context of Afghanistan, and studying the influential factors on the use of learning management systems were either limited in number or scope. Hence, no unified 
view has been found on the potential challenges of using the countrywide system developed by MoHE named HELMS as a learning management system used during the covid-19 pandemic. Besides, no research has been conducted to determine the factors influencing the use of the HELMS among both lecturers and students. This, in turn, identified a gap in the knowledge of understanding the challenges and factors influencing the use of the HELMS. Also, to the best of our knowledge, there has been a limited number of research on studying the challenges and factors influencing the usage of learning management systems from different perspectives of university managers, educators, and learners. Based on the problems stated, this research aims to find answers to the following questions:

1. What are the main challenges that face the usage of HELMS during the Covid-19 pandemic?

2. What are the key factors influencing the use of HELMS among both educators and learners?

To address the above research questions, the main objectives of this research are outlined as follows:

1. To inspect the challenges of using HELMS during the covid-19 pandemic from a managerial perspective.

2. To investigate the major factors influencing the use of the HELMS among both students and lecturers.

The rest of the paper is comprised of the following sections: Section II gives a brief understanding of the E-learning concepts and previous literature. Section III explains the methodology of the study in detail. Section IV shows the result of the conducted research. Section V presents the discussion, which is followed by recommendations, limitations, and future research directions.

\section{Literature review}

\subsection{E-learning and learning management systems}

Learning is defined as the process in which people earn new skills and knowledge to improve their capacity. Learning outcome and performance are the major measures that explain the effectiveness of the learning process (Kamba, 2009). As technology enters the field, many aspects including the education sector were affected. As a result of this alteration, the traditional learning scenario turned into a more technology-oriented way so-called E-learning (Rosenberg \& Foshay, 2002). Rosenberg and Foshay (2002) defines E-learning as a network phenomenon that utilizes the internet as the medium for distribution of materials and information to reach enhanced performance. They mention that E-learning is cost-effective and allows the stakeholders to access education anywhere and anytime. Besides, enhanced 
responsiveness to changes, improved accessibility, and value-based provision of service are also listed as the unique advantages of E-learning (Rosenberg \& Foshay, 2002). Computer-based training, internet-based education, web-based training, and recently mobile-based training are the major ways that education can be conveyed. Electronic learning comprises a variety of teaching activities through electronic tools to move education from an industrial age into the age of information society. E-learning platforms also are known as Learning Management Systems (LMSs), which are online web-based or mobile software systems using the internet to give the ability for both instructors and students to participate in teaching and learning. Teachers in LMSs can manage course materials and other aspects of instruction. On the other hand, students can use course material uploaded by instructors and participate in other activities initiated by the instructor such as quizzes, home works, assignments, chats, forums, and much more.

\subsection{Review of literature on E-learning challenges}

Various studies have been conducted on investigating the challenges of using learning management systems or experiencing E-learning among different groups of stakeholders. Research funded by MoHE (Ministry of Higher Education) of Malaysia investigated the status, trends, opportunities, and challenges of implementing E-learning in Malaysian higher education institutes (Mohamed Amin Embi, 2011). Qualitative approaches including document analysis, interview, and observation were utilized to uncover the hidden challenges toward the use of E-learning. Challenges were investigated in terms of the policy, governance, LMS, training, e-content development, integration in teaching, quality assurance, and plans. Lack of E-learning policy, low level of E-learning policy awareness, lack of effective governance model, lack of coordination in the management of technical resources in learning management systems, lack of E-learning training policy, and lack of clear policy for the development of e-content and monitoring the quality of e-content were the key challenges identified in Malaysian higher education institutes. Snoussi (2019) studied the challenges that universities face regarding the adoption of a learning management system in four private universities in the UAE. Face-to-face and online interviews were held with 54 participants including deans, HoDs (Heads of Departments), and program directors of the universities. She found that lack of students' self-discipline in online systems, the inconsistency of learning management systems with some academic programs, limited use of Arabic language, and technical literacy were the basic challenges that universities face in the use of learning management systems (Snoussi, 2019). Almaiah et al., (2020) studied the challenges facing E-learning systems during the covid-19 in Jordan and Saudi Arabia. Students, faculty members, IT experts, and policymakers were the participants of the study. The results indicated that the lack of financial supports, change management issues, and technical issues associated with learning management systems were the key challenges faced by Saudi Arabian and Jordanian institutes. A study by Almanthari et al. (2020) investigated the teachers' barriers to E-learning from four different aspects of the school, curriculum, student, and teacher-related perspectives. The study found 
out that lack of teachers' knowledge, lack of confidence, teacher's bad experience with E-learning, and convince of E-learning use were the key personal challenges toward teachers in Indonesia. In addition, lack of consistent internet connection, lack of technical support, and incompatibility of textbooks with E-learning were top school-related barriers. Based on this research, student's low level of knowledge on E-learning and lack of access to computers were the two top barriers from students' perspective. Alqahtani and Rajkhan (2020) found that technology knowledge management, high level of awareness between both students and lecturers, demand for a high level of information technology assistance, and support from management officials were the key success factors of E-learning during the covid-19 pandemic. Dhawan (2020) explored the strength, weaknesses, opportunities, and challenges of online learning during covid-19. The result of the research shows that unequal distribution of ICT infrastructure, quality of education, digital divide, lack of welldefined policies, and standards, and technology cost were the key barriers to online learning. Research by Beebe (2010) looked into the status of E-learning in Afghanistan. Based on the findings, she concluded that lack of E-learning policy, lack of appropriate infrastructure, and lack of skills in the use of E-learning among educators were the key barrier on the way to the successful implementation of E-learning in Afghanistan. Besides, Sokout and Usagawa (2018) have provided an overview of the current status and examined the potential challenges of E-learning in the polytechnic university of Afghanistan by holding an investigation on the pilot implementation of Moodle LMS and identifying its potential challenges. Based on their findings, Low-reliability level on students' perception of E-learning, scarcity of data source in the analysis of educational data uploaded into the system, lack of appropriate infrastructure, low level of quality of service, pedagogical and human resource challenges, and maintenance issues were the key challenges identified in this study. Although the above researches highlighted the most important challenges toward a successful implementation of E-learning, the current study aims to add new contributions to the current literature in exploring the potential challenges of successful E-learning service, which is the HELMS countrywide implementation in Afghanistan public universities.

\subsection{Review of literature on factors influencing the use of E-learning}

A considerable amount of literature has been published on studying the factors influencing the adoption or usage of e-learning systems. Almaiah et al., (2020) studied the factors influencing the adoption and use of E-learning among educators and learners through a qualitative approach by conducting interviews. The result revealed that trust factors (trust of internet, security, digital signatures, electronic payment, law, and regulations), E-learning system quality factors (efficiency, usefulness, ease of use, reliability, content design), self-efficacy factors (awareness, training programs), and cultural factors (ICT literacy, e-society, social media) were the key factors that have highly effected the use of E-learning among both educators and learners. According to Almaiah \& Alyoussef (2019), course design, course content support, course assessment, performance expectancy, and facilitating conditions 
were the key influencing factors affecting the actual use and use behavior of E-learning systems among students at King Faisal University (Almaiah \& Alyoussef, 2019). In the context of Afghanistan, research by Alariqi.et al. (2019) has conducted a study on understanding the impact of individual, technological and organizational factors on the effectiveness of E-learning among students in higher education institutes of Afghanistan. The findings show that each of the individual, technological, and organizational factors has a significant impact on the level of E-learning effectiveness. Taat and Francis (2020) studied the factors influencing the acceptance of E-learning among students in Malaysia and found out that system usability, lecturer's characteristics, system quality, information quality, and technical support have an impact on the acceptance of e-learning. Evidence also indicates that perceived benefit in terms of course content, time, and course simplicity are other influential key factors on acceptance of e-learning (M. A. Almaiah \& Al Mulhem, 2018; M. Almaiah \& Alyoussef, 2019). Recent research by Thongsri et al. (2019) studied the difference in perception and behaviors of STEM (science, technology, engineering, and mathematics) and non-STEM students. The findings revealed that computer self-efficacy and perceived usefulness of E-learning are major factors influencing the acceptance of E-learning between both STEM and non-STEM students. They concluded that non-STEM students are more at risk of missing the E-learning benefits. Another study in the context of Iraq has found out that perceived usefulness, perceived ease of use, subjective norms, quality of information, quality of the system, technical support, and self-efficacy have a major influence on behavioral intention to use of the E-learning systems among students (Ameen et al., 2019). University readiness has also been proved to have an impact on students' attitude in using e-learning platforms (Al-araibi et al., 2019).

On the other hand, Meriem \& Youssef (2019) identified major barriers from the teachers' perspective in the context of Abdulmalek Essadi University in Morocco. According to the author, lack of technical support, lack of institutional support, communication issues in spreading the e-learning strategy and policies, resistance to change, lack of regulations, lack of culture in sharing, lack of E-learning awareness, and low computer skills are major factors that cause reluctance in adoption to E-learning. Lack of technical support, described as unavailability of required resources for content making and internet access has also been found significant (Eltahir, 2019). Findings of research in Malaysia indicate that the major factors influencing the use of E-learning among lecturers are course-related (course design, course content, course support), social and cultural factors (instructors' belief, university rules \& regulations, new roles of instructors and teachers in e-learning, laws relevant to e-learning), and technological factors (internet access, cost, and software skills) (Aldowah et al., 2019). Research has also found that lecturers face challenges in terms of ICT and e-learning infrastructure, financial, lack of operational e-learning policies, e-content development, and internet connection challenge in the context of Russian universities (Vershitskaya et al., 2019).

The above researches highlight the most significant factors influencing the adoption of E-learning. However, there is a need for a detailed understanding of major factors influencing the use of HELMS in Afghanistan among both lecturers and students. 


\section{Research methodology}

A qualitative research methodology was used to attain the objectives of this study. This research used qualitative research methods to reach both objectives of this study. The qualitative research method was used to undermine the challenges of using HELMS from the perspectives of managerial staff and identify potential factors influencing the use of HELMS among both educators and learners. The qualitative research method is the application of a variety of methods including interviews (individual or focus groups), participant observation, and document analysis to understand and describe meanings, relationships, and patterns in the data (Tracy, 2013). Qualitative methods have several advantages including studying deeply the context, revealing the hidden impact of culture on the research problem, disclosure of more salient issues, useful for accessing the tacit feelings associated with the subject, and are recognized as the best method to understand the world, society, and institutions (Leavy, 2017; Tracy, 2013). Besides, in the context of information system research, qualitative research helps to have a detailed understanding of how users of information systems perceive and evaluate the system and is the only way that we can extract the influence of social and organizational context on the system use (Kaplan \& Maxwell, 2006). Figure 1 shows the research design of this study.

\subsection{Areas of investigation}

To determine the challenges of using HELMS, the following six dimensions were identified from the literature as the key areas of investigation, which are listed as policy, governance model, organizational culture, technical, quality of service, and

Fig. 1 Research design

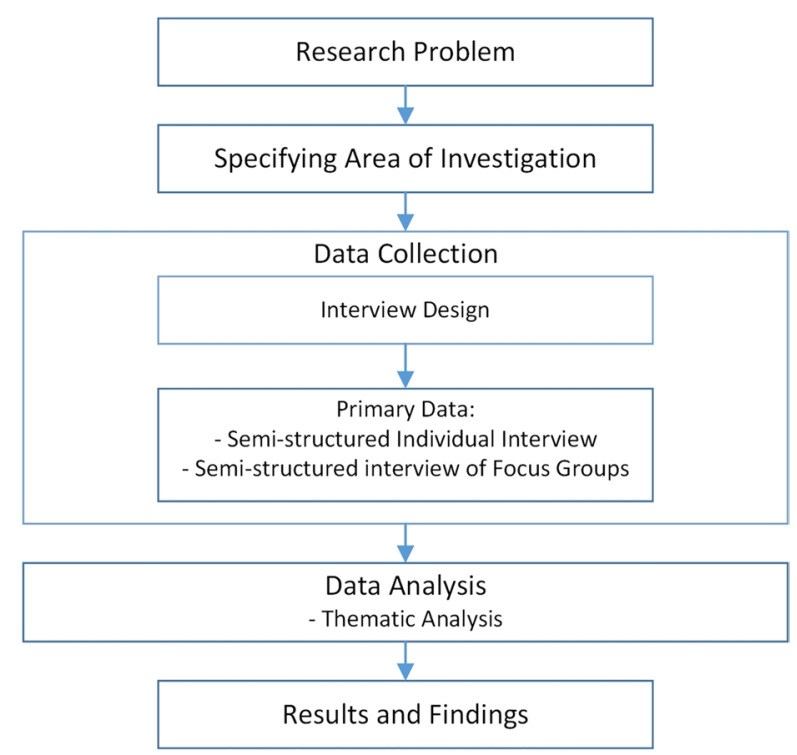


skill. First, policy is defined as a document that includes all necessary guidelines for an institution to gain certain results as part of the organizational goals and objectives. Policy existence has a serious impact on the successful implementation and use of E-learning (Rosenberg \& Foshay, 2002; Roumell \& Salajan, 2016; Shraim \& Khlaif, 2010; Wahab et al., 2011). By the policy-related issues, the literature indicates studying the challenges regarding the existence of policies, guidelines, business process, and strategic management of learning management systems in an organization. Second, the governance model describes how the e-learning is aligned as part of the educational system and describe the ownership model that represents the E-learning platform in an educational institute (Alaeddini \& Kardan, 2010; Rosenberg \& Foshay, 2002; Wahab et al., 2011; Weil \& Ross, 2004). Challenges in governance structure and the role of stakeholders were analyzed as part of the HELMS governance model. Third, Organizational culture refers to the habits, beliefs, and values of the organization (Hofstede et al., 2005). Literature indicates that learning organizations, which represent a part of an organization's culture, are more successful in integrating E-learning into their work culture (Leacock, 2005; Lin et al., 2019; Rosenberg \& Foshay, 2002). Besides, other pieces of literature found that organizational culture and promoting the organizational learning process enhance the commitment of employees (Lau et al., 2017), and it was also revealed that organizational culture can significantly enhance the operation of learning organizations (Chang \& Lee, 2007). Therefore, the need to explore cultural challenges is said to be critical for evaluating the challenges of HELMS. Forth, The technical aspect refers to infrastructure issues in universities for implementing E-learning through the HELMS platform (Almaiah et al., 2020; Mailizar et al., 2020; Mohamed Amin Embi, 2011). Fifth, Quality of service indicates the quality issues related to learning, teaching, and learning material of HELMS. As part of this area, quality of the content (quality of material uploaded, diversity of material, compatibility of learning material with the learning environment, material accessibility), quality of service (the quality of educational service through HELMS), and quality of information system (usability, availability, security, reliability, and accessibility) were discussed (DeLone \& McLean, 1992; Pham et al., 2019; Sulaiman et al., 2011). Finally, by skill dimension, this research refers to human resource potential for managing and using HELMS (Beebe, 2010; Sokout \& Usagawa, 2018). On the other hand, to study the factors influencing the use of HELMS among both lecturers and students, the area of investigation is not previously defined, but this research is supposed to investigate the factors around the foci of the second research question, concerned about the factors affecting the use of HELMS among lecturers and students.

\subsection{Context of the study}

The data was gathered from Four public universities in Afghanistan named Bamyan University, Kunduz University, Kabul University, and Herat University. The universities mentioned are among those, which started to use HELMS as their medium of education during the covid-19 pandemic. The selected universities include two major universities (Kabul University, Herat university) in highly urbanized cities of 
Kabul and Herat. Besides, two universities (Kunduz University and Bamyan University) in less urbanized cities were also considered as part of the context of the study.

\subsection{Participants of the study}

The interview questions were designed to ask university administration (chancellors, vice-chancellors, Heads of departments, deans of faculties, HELMS evaluation committee members), lecturers, and students. As a result of data collection, 3o administrative staff, 45 students, and 25 lecturers of different backgrounds and demographics were included in the interview. The sample size was highly decided based on the aims of the study, sample specificity, use of established theory, quality of dialogue, amount of data collection, and analysis strategy (Malterud et al., 2016; Quick \& Hall, 2015). The interviewees were selected having different backgrounds including technology, social sciences, applied science, and other fields of educations, which will further help us to have a more general view of the factors and challenges facing the use of the HELMS. In addition, the interviewees were selected such that they have used HELMS and have enough knowledge and experience on HELMS to express their thoughts and beliefs. Following Table 1 shows the information about the participants of the interview.

Table 1 Interview participants of the study

\begin{tabular}{lllll}
\hline Interview Participants by University & & & \\
\hline University & Administrative staff & Lecturers & Students & Total \\
\hline Bamyan University & 15 & 10 & 10 & 35 \\
Kabul University & 5 & 6 & 10 & 21 \\
Herat University & 5 & 5 & 15 & 25 \\
Kunduz University & 5 & 4 & 10 & 19 \\
& 30 & 25 & 45 & $\mathbf{1 0 0}$ \\
Interview Participants by Group & Values & & & Percentage \\
Groups & Male & Count & $63 \%$ & \\
Gender & Female & 63 & $37 \%$ \\
Field of study relevance & Technology and Engineering & 37 & $22 \%$ \\
& Social Science & 22 & $33 \%$ \\
& Applied Science & 33 & $28 \%$ \\
Education & Other & 28 & $17 \%$ \\
& Completed Bachelor or in Progress & 55 & $55 \%$ \\
& Master Degree & 39 & $39 \%$ \\
& Ph.D & 6 & $6 \%$ \\
\end{tabular}




\subsection{Semi-structured interview}

To reach the objectives of this study, semi-structured interviews with both individuals and focus groups were used as the data collection method. As part of the semi-structured interview, questions were designed in such a way to not follow a rigid path, rather it was designed following TEDS (tell, explain, describe, suggest) approach. This method makes the interview more interactive and finally leads to an increase in the quality and quantity of data gathered. The interview questionnaire included questions, which were reflecting the research objectives of the study and were seeking to find answers to the research questions. During the interview, administrative employees of the universities were asked about the challenges that they face in using the HELMS at the six dimensions mentioned in the area of investigation section. The questions focused on asking the existence of the policy, guidelines, and procedures about HELMS, the governance model used for determining the structure, roles, and responsibilities of stakeholders at HELMS, the existence of challenges in beliefs and habits as part of organizational culture, technical, human resource skills for managing and use, and quality aspects of HELMS.

On the other hand, students and lecturers were targeted for understanding the factors influencing their use of HELMS. 45 students and 25 lecturers were asked about the major factors that affect their usage behavior toward HELMS, their reason that they do not use it, and what are the major weakness in the HELMS to make them demotivated regarding the HELMS use. The semi-structured interview was set up to be open for exchanging questions among the researcher and interviewee for a better understanding of the research questions and gathering more data. Interviews were conducted by phone, online (using skype), and face-to-face considering the WHO guidelines (wearing masks and keep social distancing). The researchers also set up focus groups with members of the HELMS administration committees in the university and the HELMS evaluation committee in the faculties with a minimum of 5 members in each focus group attended the data collection. The interview was recorded with their permission by mobile phones such that their anonymity should be considered. Final data included the transcription of the records and also contains the texts which were noted down during the discussion with the participants.

\subsection{Thematic analysis}

Thematic analysis was used as the technique for the analysis of qualitative data. To explore deeply the challenges and factors influencing the use of HELMS, performing the thematic analysis on the interview of participants will provide a detailed and nuanced meaning of data and capture important themes from the data collected (Vaismoradi et al., 2016; Vaismoradi et al., 2013). Five major steps were done as part of the thematic analysis on collected data, which are familiarizing with data, code generation, searching for themes, theme revision \& naming, and generating the final report. The whole thematic analysis is concerned based on the concept of theme. The theme represents the major 
subject that was expressed by the data related to the research questions. Thematic analysis was performed manually on the collected data. In the first step, the researchers make themselves familiar with the data by transcribing the interview, reading the transcribed text, and highlighting the initial ideas related to the research question. Soon afterward during the coding step, phrases and sentences were highlighted and labeled using the relevant words to the challenges and factors influencing the use of HELMS. In the third step, identified codes were categorized under the a) two specific themes emerged from the research questions which are challenges facing the use of HELMS and factors affecting the use of HELMS among both students and lecturers, 2) sub-themes, which are the sub-groups including six specified dimensions and the specific group of people (Students and lecturers) that are under the two specific themes mentioned before, and 3) factor groups, which are themes emerged from the data collected concerning the factors influencing the use of HELMS among students and lecturers. Then, as part of the theme development stage, two variations of thematic analysis including deductive and inductive thematic analysis were used to analyze the data in this study. Deductive thematic analysis is a way to identify, analyze, and report patterns in pre-defined themes to get the essence of the gathered data concerning the research objectives (Vaismoradi et al., 2013). To analyze the qualitative data obtained through the interview for investigating the challenges of using HELMS, deductive thematic analysis was chosen. In contrast, inductive thematic analysis was performed to analyze the qualitative data on the interview of both lecturers and students. Inductive thematic analysis was used to identify the factor groups as part of the analysis. Figure 2 shows the whole process of theme development as part of the thematic analysis performed on the collected data. In the fourth step, the codes were reviewed, if they match the sub-themes and factors groups to get a more consistent and reliable result. Besides, the names are also checked if they properly reflect the result gathered. Finally, in the reporting step, the final analysis was done on extracted data considering the research question and a report of analysis was produced.
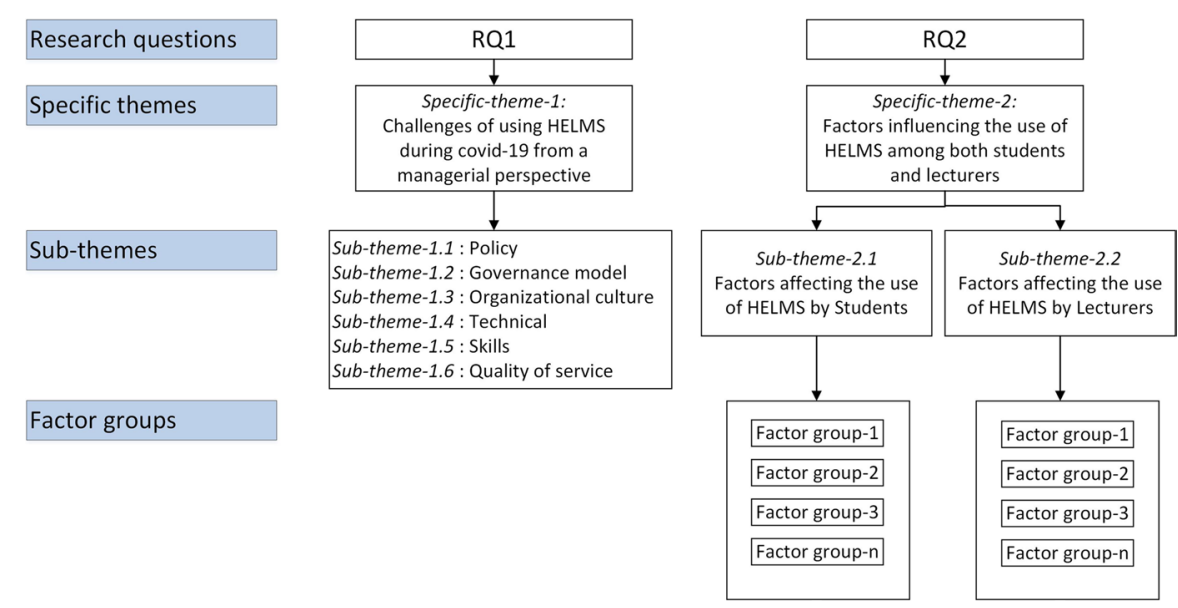

Fig. 2 Theme development in thematic analysis 


\section{Results}

In this section, results from the analysis of qualitative data are demonstrated. As part of analyzing the challenges of using HELMS, challenges are extracted, grouped, and demonstrated in the six major dimensions. Finally, the result of the interview with students and lecturers were also analyzed and presented to demonstrate the influential factors.

\subsection{Findings of the critical challenges facing the usage of HELMS during the COVID-19 pandemic}

The objective of this part of this research was to investigate the challenges of using HELMS during the covid-19 pandemic in Four Afghan universities. Challenges were explored by having an in-depth interview with managerial staff of universities including HELMS committee members, heads of departments, deans of faculties, university chancellors, and vice-chancellors at mentioned universities. As stated in the area of investigation under methodology, six major areas or themes were defined for studying the challenges of the HELMS. Challenges in each predefined theme were identified, explored, and justified.

Policy Findings of the interview with the university authorities indicated that no written document that contains the required policies, guidelines, and procedures for learning and teaching through HELMS exist to act as the roadmap for implementation and use of HELMS. Neither MoHE (Ministry of Higher Education) nor universities and their programs worked on developing appropriate documents for using learning management systems. Although well-structured policies, procedures, and guidelines were defined for on-site learning, no formal written document exists to clarify the goals, vision, values, objectives, guidelines, roles, responsibilities, and operational procedures for delivering the education through HELMS. The gap caused by the lack of formally approved written policies, procedures, and guidelines that define the roadmap, roles, responsibilities, values, and activities for HELMS, is a major challenge that universities face in the successful implementation of HELMS.

Lack of policy was said to be a critical challenge toward the success of HELMS. No policies were found concerning the HELMS use and management, HELMS awareness, HELMS adoption, HELMS quality control, teaching through HELMS, learning through HELMS, and monitoring and evaluation of students' and lecturers' activities in HELMS. It was also mentioned that no standards have been defined to describe the quality of e-content developed by lecturers to be uploaded on the HELMS. Lack of mechanisms to define expertise exchange among lecturers and students and lack of a well-defined policy for increasing participation of students and lecturers in the HELMS were also discovered to be a major problem. Evidence showed that managing bodies and university administration are informally managing HELMS by following informally non-written ad-hoc oral policies, guidelines, and procedures. 
Participants have also stated that they are not aware of any existing policies that are designed for E-learning by any managing bodies including MoHE and universities. The result of the interview revealed that the developed E-learning policy has not yet been distributed among the universities or other bodies of higher education. The majority of participants asserted that they were not aware of any policy related to E-learning or HELMS and they think that it is the responsibility of MoHE to develop guidelines and policies along with the new service that they provide or the changes that they bring as part of their change management plan. This, in turn, indicates a serious problem in policy communication, which is a major challenge toward policy implementation and success of a policy. The result of the interview with officials also depicted that E-learning, as a broad terminology is included in the strategic plan of universities and faculties. However, in the majority of cases, there are no specific objective and related actions to be undertaken for promoting E-learning. On the other hand, it is worth to be mentioned that, implementing and using learning management systems have not been anticipated as specific objectives or actions in strategic plans of almost all university bodies including faculties and departments.

Lack of well-defined procedures has caused trouble in managing HELMS. To illustrate, participants said: "the lack of a defined procedure for user creation and credential distributions created serious trouble for university administration. The presence of inactive users without physical existence or creation of duplicate users were troublesome". Based on the evidence, many inactive users were created for those students who were on the primary list of admitted students by the Kankor exam, but they are not current students due to change of university, denying the admission, and other reasons so that they do not exist now in the current batch of the department. The same challenge exists for lecturers, in which many duplicate users were created for lecturers. Technically, duplicate or extra-created users for students and lecturers led to incorrect reports regarding the overall percentage of students participating in HELMS, and it created extra work for departments in deactivating absent users. "Faculty secretariat and administration staff creating batch lists originated this problem”, respondents said. As another managerial challenge, no procedure was defined for distributing the user credentials. The username and passwords for each user were expected to be sent by HoDs to only the expected student personally via email or text message. However, HoDs due to the lack of a unique procedure defined, made the credentials list of each batch available for the public. Because of this act, the privacy of the users was disregarded. "Due to this carelessness act that occurred by the majority of HoDs related to lack of policy, a huge load of work by the HELMS administrator was to respond to users for their lost passwords and recovering accounts of students", said one of the IT and HELMS administrators in the universities.

Organizational culture Lack of commitment was the major cultural issue found in the universities at different levels regarding the use of HELMS. High-level management expressed that heads of departments and deans of faculties were subject to blame for not fulfilling their responsibility by their absence in the faculty or not performing daily monitoring on the use of HELMS. Participants have indicated that the majority of the authorities including deans of faculties and heads of departments 
have shown their lowest level of concerns in terms of encouraging to use of HELMS and assessing activities of teachers and students in HELMS. Lack of commitment issues in the organization has caused a decrease in motivation among the majority of stakeholders for using the HELMS. In addition to the lack of commitment shown by staff toward the HELMS system, the students had also the same feelings on their way to use the system. According to one of the HELMS administrators, "Among the tickets coming to the HELMS administration office, most of them were titled as forgotten passwords". Respondents believe that one of the key reasons behind this behavior can be their low level of interest in HELMS and lack of commitment toward it.

Resisting to changes in higher education institutes was the other key cultural issue that university administration faced during the HELMS use. Participants expressed that the majority of low-level and middle-level staff including lecturers and heads of departments frequently expressed their disinterest in changing their traditional way of teaching to using HELMS. Respondents stated that some of the high-level officials even revealed that changing traditional learning to online learning was not an acceptable task for them. Lack of enough knowledge on e-learning, custom orientation rather than an interest in exploring new things, and lack of familiarity with HELMS were said to be the key reasons behind their resistance to change. Some of the respondents stated: "The high degree of people-orientation rather than task orientation in decision making at the high level of university administration has doubled this problem such that final decisions and actions were more likely to be subjective rather than considering the benefits of students by thinking of HELMS implementation and its use in the university". Based on the previous statements, resistance to change was one of the key cultural issues found to block the process of change management by not adopting HELMS as a new service inside the higher education institutes.

In addition to lack of commitment and resistance to change, the low level of willingness in exchanging expertise demonstrated by lecturers and faculty administrations around the use of HELMS was the other cultural issue that the majority of the participants agreed on it. Although some departments were found successors in adopting HELMS, lack of dedication and willingness in exchanging their expertise with other staff whom they are in a lower level of adoption has kept the success rate of the whole university in a lower stage. A university official said: "Some lecturers have the skills in using HELMS and creating e-content, but they are not willing or they are not concerned to provide us the necessary pieces of training in the university to build the capacity among all members". respondents stated: "university officials were also less concerned about the expertise exchange as a way to enhance skills required for using HELMS among the lecturers".

Low level of respect to the degree of hierarchy is another cultural issue that respondents believe to have a serious impact on the use of HELMS. Lecturers, heads of departments, and deans of faculties in some cases deny or feel inattentive regarding the orders and decisions in the higher degree of the hierarchy inside the universities. As such, that the people in the organization work outside formal channels with loosely defined job responsibilities and accept to challenge the higher level of authorities. This informally accepted tradition in the higher education institutes 
had made change management difficult for university administration in most cases. Respondents stated that some of the lower-level staff have refused to accept HELMS and denied the rules and decisions accepted by the academic council of universities regarding HELMS use. "If not refusing to accept the decree, they act as such they do not feel responsible to decisions in a higher level of decision making”, respondents stated.

Technical The interview with relevant participants also uncovered some hidden technical problems that caused trouble in using HELMS. These technical problems are related to the usability of the HELMS system. The absence of a password recovery function on the system itself was one of the key challenges faced by users and resulted in a high load of work for the HELMS administrator and a delay in the user's presence on HELMS. Although email addresses are associated with each user account, the HELMS system administration has not yet worked on account recovery tools using a third-party application or proprietary webmail service by the HELMS system. This problem, which was mainly faced by students, has caused a huge load of work for a range of staff including the head of departments and HELMS administration team in the university.

Skills The interview conducted with participants indicated that the management staff including the HELMS administrators had no enough prior knowledge and expertise of HELMS in their early days. Both users faced a challenge in their daily activities of administration and reporting. HELMS administrators stated that they had a low level of experience in course management, user management, and creating reports with HELMS. Although reports are the key to the success of HELMS in analyzing the current situation, lack of skills in creating complete and helpful reports had caused a lag in heading toward success. On the other hand, during HELMS administration and reporting, users faced problems in understanding terminologies, functions, and other HELMS customization. Besides, the lack of technically trained staff provided by universities for training and administration purposes was the other key barrier faced in universities. Universities expressed that they face a shortage of skilled trainers in training the use of HELMS and development of e-content for HELMS. According to them, "lack of skilled trainers has seriously caused HELMS literacy to remain at a lower level. Yet, it resulted in a low level of willingness to use HELMS among lecturers and low quality of e-content uploaded in the HELMS”.

Governance model An informal governance model was applied in universities for clarifying the roles, responsibility, and ownership of HELMS. The applied informal governance model distributed the responsibilities among a limited number of stakeholders including students, lecturers, HELMS administrators, University chancellors, and HELMS evaluation committees. Students have been defined as the primary users of HELMS responsible to follow the classes online by accessing the resources. Lecturers, on the other hand, are responsible for creating e-content and making them accessible online. HELMS administrator, who is the IT administrator of the university is responsible for technical tasks related to the HELMS. Furthermore, the 
university chancellor was technically enrolled in all courses in the university and act as the watcher of the course contents. In addition, the HELMS evaluation committee includes representatives from the faculties and university chancellor leading this committee. This committee is the main management body of HELMS which is responsible for monitoring the activity of students and lecturers in the HELMS. The committee is responsible to take proper actions based on the result of evidence gathered during the monitoring in order to enhance the efficiency of the HELMS. From a system administration perspective, the architecture of HELMS was designed such that the HELMS core management team (in charge of deploying and management of the HELMS) exists at the top level and the HELMS administration team of universities (comprised of IT administrators in the universities) are in the lower level of administration.

The result of the interview shows that an informal non-written model was applied as the governance model of HELMS. First, the key issue found with the applied governance model is mentioned as having no clear definition for the roles and responsibilities of heads of departments, deans of faculties, faculty administration staffs, and university administration (Chancellor and vice-chancellors of student and academic affairs). Although they are physically involved and concerned by the activities of students and lecturers in the HELMS, no clear role has been defined for them. Secondly, in the applied model of governance, IT administrator and HELMS administrator are combined roles, which should be distinguished due to the high load of work for each role. According to HELMS administrators, "more than 100 tickets of problems come daily by students and lecturers". The third main issue found with the governance structure of HELMS in university is the ownership rights of the HELMS committee. Although this committee has no direct access to lower operational users and their members have no access defined in the HELMS to actually monitor courses inside the university, they are responsible to observe the activities of both students and lecturers in the whole university. A member of the committee said, "Except for the University chancellor who has been enrolled as a student for all courses inside the university and can monitor the content of the course, other members of the evaluation committee had not been granted access to HELMS courses and their content for monitoring". Despite giving access to the University chancellor for monitoring the content of the course, it seems impossible to monitor a large number of courses offered inside a university by one user. Forth, from a higher administrational perspective, the HELMS administration staff of the universities mentioned their limited authority and access to the system as the key challenge that they have faced in HELMS administration. To explain, they said: "for completing some basic tasks there is need to contact Poly Technic University, where the team for Central HELMS administration exist and ask them for help. Sometimes it takes time to get a response back". This, in turn, has led to delaying the daily activities of students and course administration tasks. The result also demonstrated that universities and their managing bodies have implemented ad-hoc models for managing the tasks of online learning through HELMS. Therefore, the lack of a unified detailed governance model for the HELMS has faced universities with a critical challenge in using HELMS during the pandemic. 
Quality of service Under the term of quality of service, this research has investigated the challenges related to the quality aspects of the HELMS from a managerial point of view. The quality of service was defined under three sub-themes of quality of content, quality of teaching, and quality of the system. Interviewees mentioned the existence of serious challenges in e-content development for HELMS. The contents including lectures, lecture notes, videos, and audio files were developed lacking an institutional unique identity. "Either lecturers did not include institutional identity in their content or arbitrary institutional formats were used in the e-contents", officials said. Additionally, officials stated that lecturers have not considered the diversity of the material. The majority of lecturers have just uploaded PowerPoint slides. However, PowerPoint slides only are not sufficient resources for many areas of studies. Variety of material and compatibility of the material with the learning subject has not been considered by a large portion of lecturers in many areas of studies. To illustrate, respondents stated, "for teaching subjects related to chemistry, biology, mathematics, computer science, engineering, and economics there is a need to have videos, audios, lecture notes, and lectures slide for various tasks, but there we can find just textual material in most cases". Evidence from university officials also revealed that the majority of lecturers have also had no contribution to e-content development. Participants stated, "Contents developed by other authors, e-content makers, and academic institutions were used as course material". Lack of detailed unified guidelines for e-content development in universities was so-called the reason behind all the above-mentioned problems that universities faced.

Quality of teaching is another aspect of service quality found in this research. The same as in-person teaching, teaching via HELMS requires a close relationship between students and lecturers. This relationship will help students and lecturers engage in daily discussions, feedback, support, and mentoring about daily activities. Heads of departments reported that majority of the lecturers did not engage in discussions via HELMS functions such as chat and forums. Lack of interaction between both sides of the education process is a major problem in teaching through HELMS. In addition to the lack of lecturer-student interaction, the interactions between students are also faded in HELMS, which made expertise exchange among students themselves challenging. Furthermore, irregularity of lecturers' presence in HELMS and following an unorganized timeline in uploading material was the other major issue that officials reported after evaluation of courses. Officials added that a considerable number of lecturers uploaded the whole lectures for the entire semester at once, which has led the students to gain the material all at once. This irregularity in presence of lecturers at HELMS is said to have negative impacts on the presence of students in HELMS.

Participants expressed challenges of the learning management systems as well. They highlighted the usability of the system as the major challenge that they face in the use of HELMS. Problems in interacting with the user interface of the HELMS either on mobile or web applications were mentioned as major systemrelated issues. They have stated the accessibility of HELMS with low bandwidth of internet and low download rate on data networks as the other significant issues found. 


\subsection{Factors influencing the adoption of HELMS}

As the second objective of the research, factors influencing the adoption or use of the HELMS among both students and lecturers were investigated through group and individual interviews. Demographics of participants are demonstrated in the data collection section. Factors that have an impact on the use of HELMS were grouped and identified for both students and lecturers. The following sections report the result of inductive thematic analysis performed on the gathered data from both lecturers and students.

\subsubsection{Factors influencing the use of HELMS among students}

Analysis of the evidence gathered from students through the interview showed major factors influencing the use of HELMS among the students can be grouped into eight major categories. Table 2 shows the factor groups, associated factor in each group, their definition expressed by interviewees, and the example wordings caught from the interviewee during the interview. The results showed that students are widely concerned about the factors related to infrastructure, economic factors, university management, ICT literacy, performance expectancy, and content quality out of eight major factor groups. This in turn means that access to electricity and internet, cost of internet and hardware, issues related to the management style of the university during the HELMS use, and their knowledge on use and experience with computer, internet, and HELMS were the key factors which had a significant impact on their level of use. Results also revealed that students did not expect the HELMS to be efficient and productive for them as a learning support tool, while compared to onsite education, they prefer onsite education. The students have also expressed their feelings toward the quality of the content in HELMS uploaded by the lecturers as learning material, which indicated that learning material lacks the diversity of content type and materials are more text rather than including audio and video. In addition, the students also stated facts about issues related to the HELMS system such as its usability and functionality, which is described as the complexity in the level of use with HELMS and the existence of issues while working with HELMS. The lecturers' behavior toward students described as their low level of responsiveness, was another key factor affecting the use of HELMS among students. To conclude, the results of the interview with the students demonstrated that factors influencing the adoption of HELMS among students were mostly issues related to infrastructure, economics, university management, ICT literacy, performance expectancy, and content quality. However, lecturers' behavior and LMS quality factors were not expressed to be the most controversial problems representing the HELMS. However, it is worth to be mentioned that they are still the areas of challenges faced by a considerable portion of respondents.

\subsubsection{Factors influencing the use of HELMS by lecturers}

The result of the interview done with lecturers revealed the most highly influential factors, which were grouped into five major groups. Table 3 demonstrates the factors 


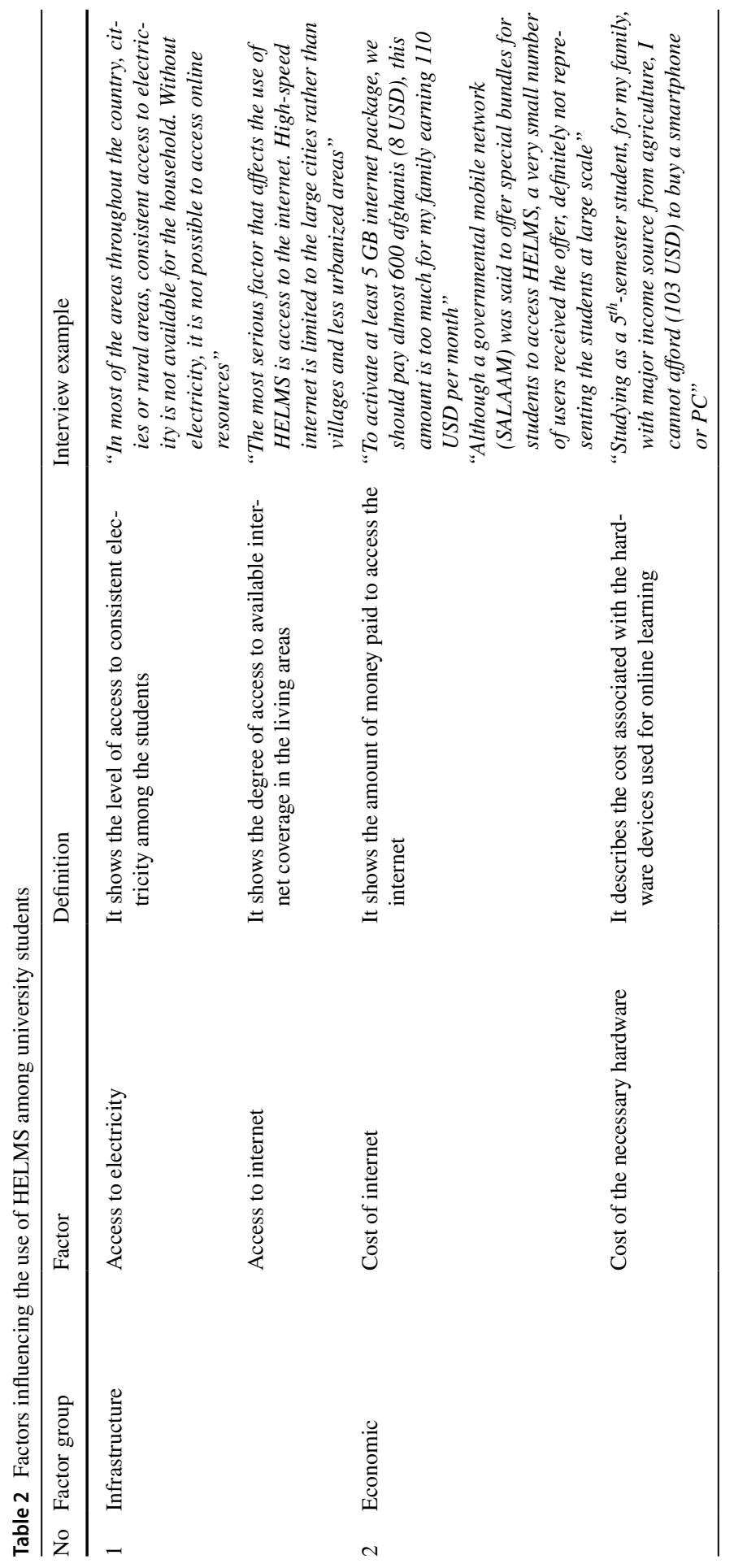




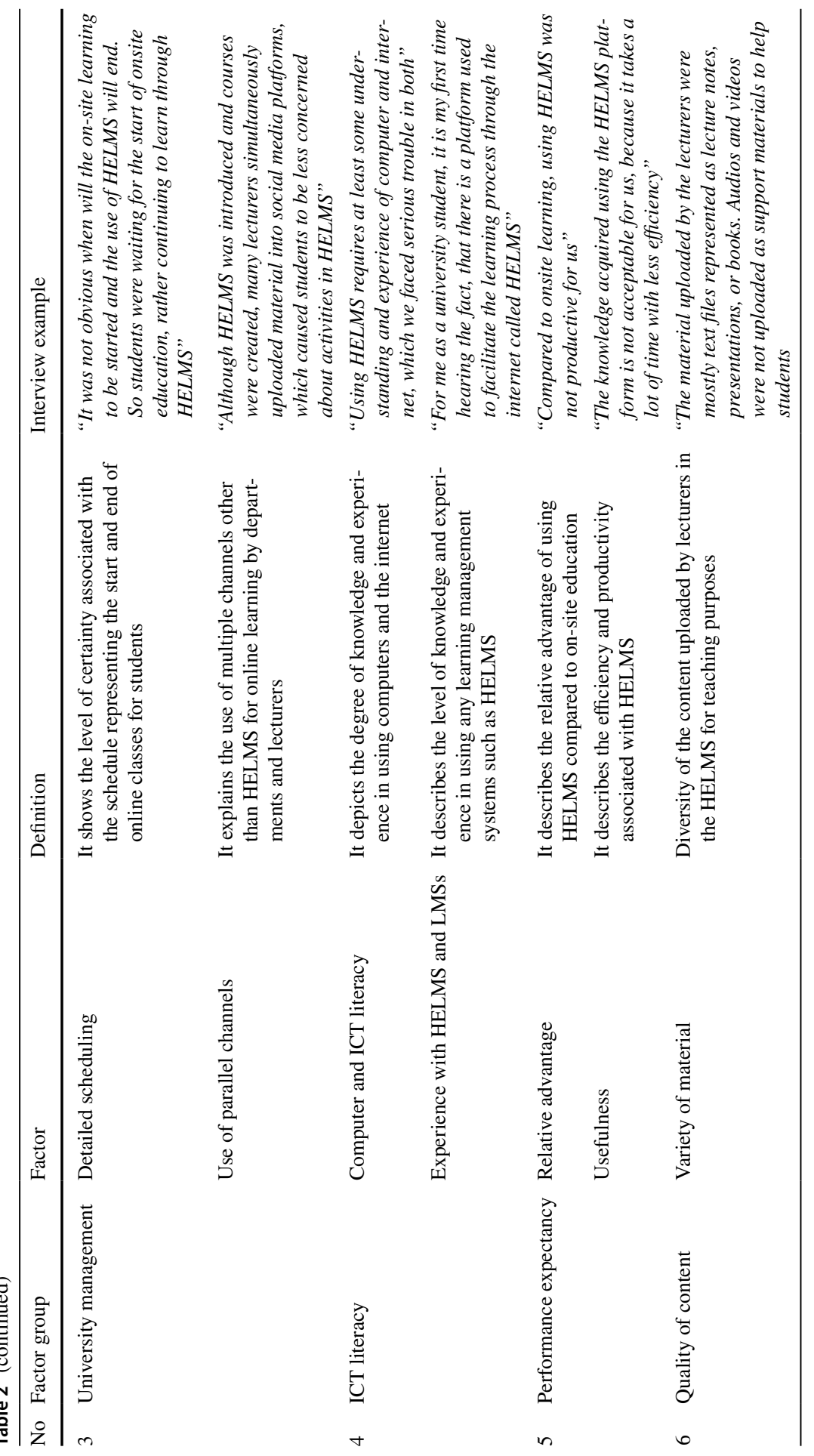




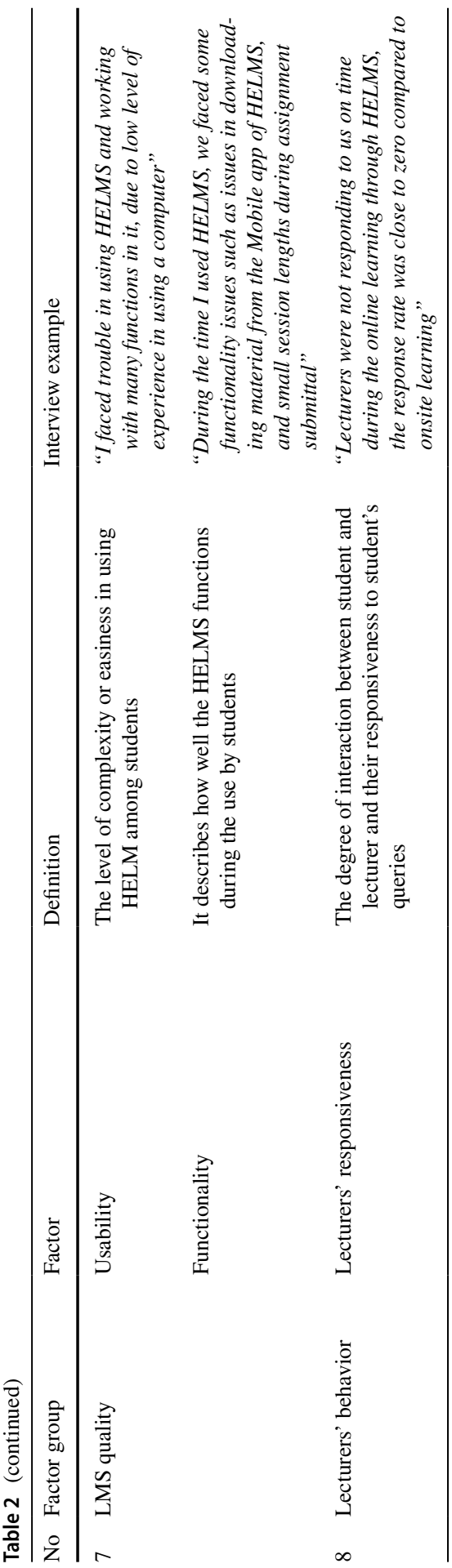




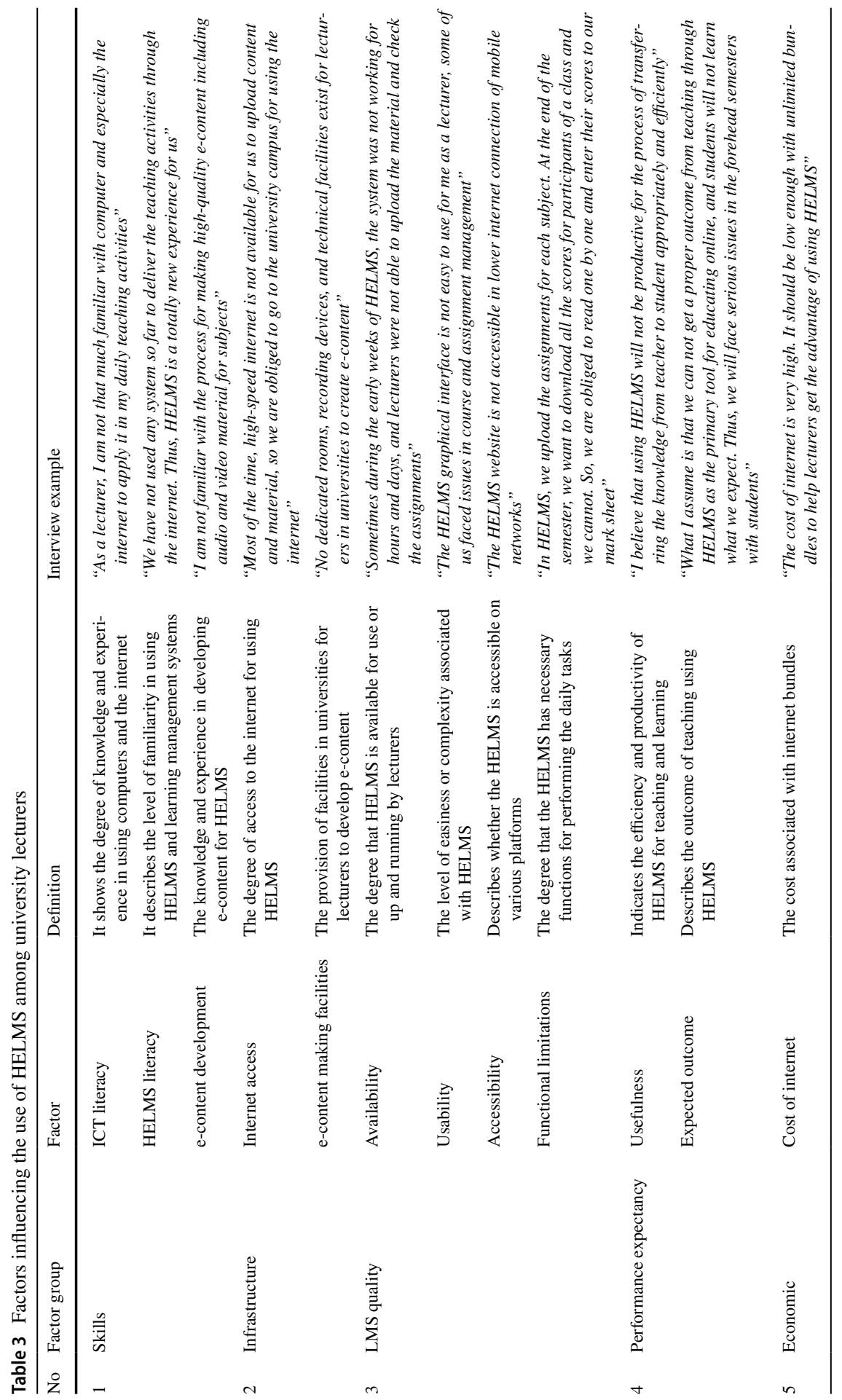


groups, factors, and their definition added with interview examples. The result of analysis on gathered data shows that factors affecting the use of HELMS among the lecturers are grouped into skills, infrastructure, LMS quality, performance expectancy, and economic categories. Based on the data gathered from the lecturers, their level of knowledge and experience with the use of HELMS and developing e-content was one of the key factors having a significant impact on the use of HELMS. Some respondents have also stated that lack of knowledge and experience with the internet and computer critically influenced their desire to use HELMS. Access to consistent internet and electricity were the other major factors representing the infrastructural issues among the university lecturers. Besides, lecturers were also concerned about the availability, usability, accessibility, and functionality of the HELMS, which were expressed as important issues in the HELMS. To illustrate, lecturers expressed issues such that the HELMS systems were not easy to use, lacking some required functions, not accessible on low internet bandwidth. They also complained about the system downtime during some periods. The level of perception in efficiency and productivity of teaching using HELMS and the potential outcome of the system was described as low, which indicated the fact that they do not expect the use of HELMS will be advantageous in terms of teaching. Economic issues were less of concern from the lecturers' perspective. However, it is a major issue that internet users in Afghanistan still face. In conclusion, major factors that were found to influence the use of HELMS among lecturers are related to skills, infrastructure, LMS quality, and performance expectancy. But the impact of economic issues on the lecturers' desire to use was not largely expressed.

Figure 3 shows the findings from the analysis of challenges and factors influencing the use of HELMS as a result of research in universities of Afghanistan.

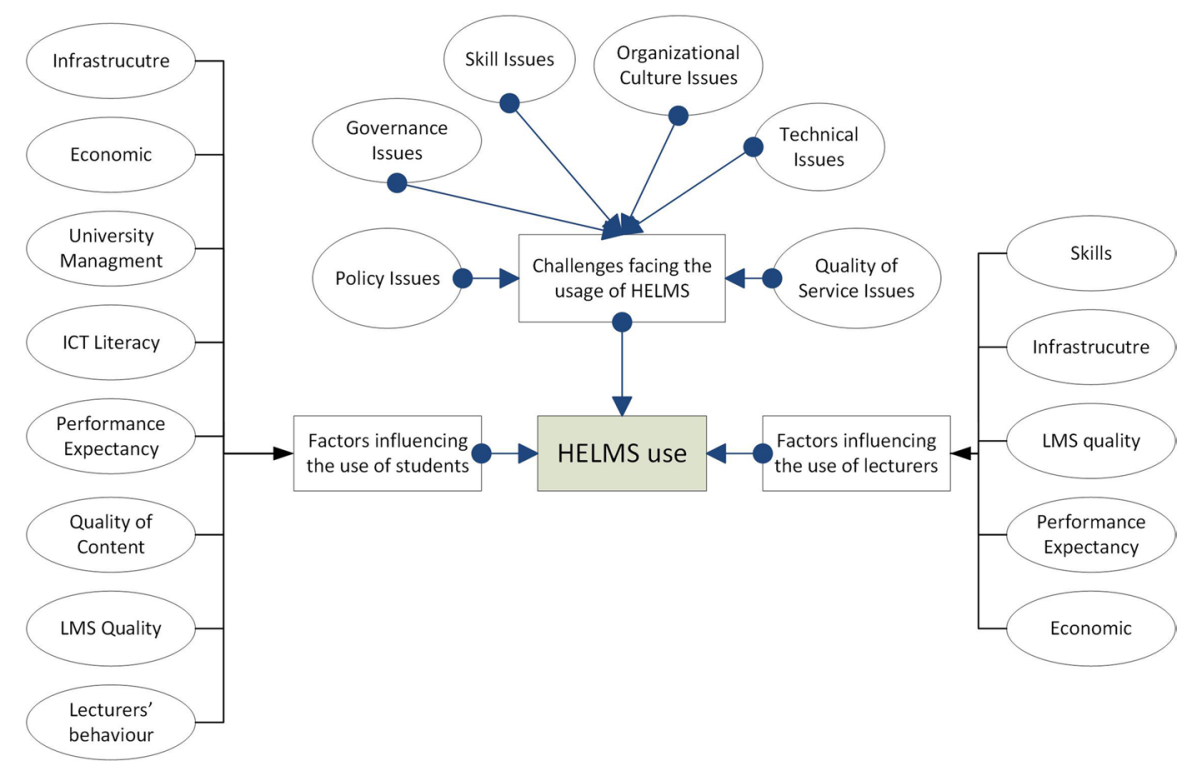

Fig. 3 Challenges and factors influencing the use of HELMS in universities of Afghanistan 


\section{Discussions}

The research has so far focused on investigating the challenges that Afghan universities have faced in terms of using the HELMS and studying the factors influencing the acceptance and use of HELMS by students and lecturers. To gain the objectives of this study, qualitative research methodology was used by conducting semi-structured individual and group interviews with stakeholders including university management, lecturers, and students. Thematic analysis was used to analyze the gathered data and group them into themes.

After an extensive and rigorous analysis of data gathered through the interviews, the lack of policy, guidelines, and detailed procedure documents regarding the implementation and management of HELMS was recognized as the key challenge toward the use of HELMS in Afghan universities. As policies act as a general guideline for achieving the goals, objectives, and result in an organization, the lack of the policy documents raised concerns in attaining the specified target in e-learning and continuation of education during Covid-19. Lack of a formally accepted and communicated policy paper even resulted in an informal non-written management model of HELMS inside the universities and resulted in facing serious challenges in the implementation, management, and use of HELMS. Research in the context of Malaysian higher education institutes proves that universities with well-formulated policies are more successful in implementing E-learning (Atan et al., 2011). Lack of serious attention from higher-level authorities of MoHE related to E-learning policy formulation and implementation is said to be the main reason behind the policy gap in E-learning implementation in Afghanistan. The result proves that e-learning adoption has not been considered as a priority for MoHE and they have not anticipated the situation such as countrywide quarantine under which online learning should be replaced with onsite education. The findings of this research are consistent with the results from previous studies (Almaiah et al., 2020; Atan et al., 2011; Beebe, 2010; Dhawan, 2020).

Evidence supports that lack of a well-defined policy has even led to other major challenges such as having an unclear and informal governance model. The result of the interview showed that the HELMS service is used without a clear definition of roles and responsibilities for all relevant stakeholders including the university chancellor, vice-chancellors, deans of faculties, heads of departments, lecturers, students, faculty administration staffs, and HELMS administrators of universities. As part of the E-learning policies, it was expected to contain a detailed explanation regarding the management and governance model of the HELMS. AS part of the governance model, the roles and responsibilities of all relevant stakeholders of LMSs should have been clarified accordingly (Atan et al., 2011). For a new service to be used inside the organization, there is a need to manage the necessary changes by revising and reviewing the guidelines and make appropriate changes inside the organization. Hence, change management is a critical responsibility of high-level officials in an organization as part of bringing a new service (Almaiah et al., 2020). Although the HELMS has been implemented and used so far as an alternative way to onsite education for delivering education during covid-19, changes have not been made into the actual procedures and 
guidelines to indicate the use of HELMS as a new component inside the organization. Rigorous efforts should be made to start using HELMS by executing a well-defined change management plan. As part of this change management plan, roles, responsibilities, and restrictions should be defined clearly for all groups of users and stakeholders with their required set of functions properly assigned. According to these results, we can infer that lack of a well-defined governance model is the other serious challenge on the way to use HELMS. The findings are supported by other researches in this field (Alaeddini \& Kardan, 2010; Wahab et al., 2011; Weaver et al., 2008).

Results also found that the absence of an inclusive policy and guideline for management and use of the system has also affected the quality aspects of the HELMS. The findings of this research revealed that the quality of service is a major challenge area. Evidence showed that serious challenges exist in the quality of the content. Irregularity in the content update by lecturers, shortage of resources in e-content development inside the universities, uniformity in e-content on the HELMS, and lack of efforts in content developments by lecturers were the key challenges in the content quality aspect. Challenges concerning the quality of content are also supported by previous literature (Mohamed Amin Embi, 2011; Sokout \& Usagawa, 2018). Previous studies show that high quality of content indeed can influence positively the willingness of students to use learning management systems (Almaiah \& Alyoussef, 2019; Taat \& Francis, 2020). Thus, the need to enhance the quality of content for the success of HELMS is critical. In addition, the result confirms that lack of student-student interaction and communication, lecturer-student interaction, and irregularity of lecturers' presence on HELMS were major challenges from a teaching quality aspect, which were also proved to be significant in other works of literature as well (Dhawan, 2020; Ismail et al., 2011; Sokout \& Usagawa, 2018). According to the previous studies, it was found that the lecturers' attitude and activity in the E-learning system positively influence the level of students' acceptance or desire to use E-learning systems (Taat \& Francis, 2020). Therefore, lecturers' participation in learning management systems can encourage the student to participate in online classes. Additionally, System quality has also been a challenge for university administration. Key concerns were revealed in terms of usability issues, availability, and accessibility. To elaborate, users believe that HELMS is not easy for them to use, and they face trouble in accessing HELMS through the low internet connection. Besides, HELMS was found to have issues in terms of availability. Possible reasons behind the system quality issues can be mentioned as deploying the HELMS on less enhanced infrastructure, the small number of management team, lack of skilled designers and developers with knowledge on pedagogical theories, and low level of skills in the HELMS administration. As several studies (De Smet et al., 2016; Taat \& Francis, 2020) confirms the result obtained, developers, designers, and system administrators of HELMS should undertake proper actions in addressing the challenges.

Moreover, lack of necessary skills to use and manage HELMS among the stakeholders has also been described as the other key challenge of using HELMS from a managerial perspective. Several reports in the less developed countries prove the claims (Aldowah et al., 2019; Beebe, 2010; Meriem \& Youssef, 2019). Results revealed that stakeholders, while a large portion of them lecturers and students, expressed that they had no previous experience in the use of learning management 
systems. Furthermore, respondents stated that they lack enough skills to use HELMS. Prior studies have noted that the level of skills among the stakeholders of the information systems has a great impact on the success of the information systems (Rosacker \& Olson, 2008; Sabherwal et al., 2006). So, the development and deployment of the system should be based on an in-depth analysis of the current situation especially in terms of users' skills. This lack of previous assessment and research on understanding the level of skills inside the universities of Afghanistan has led to challenges toward the use of HELMS. While the majority of stakeholders are not ready to use due to the low level of ICT skills, HELMS literacy skills, and e-content development skills, no pieces of training have been conducted inside the university to expand awareness about E-learning and train the use of HELMS for all groups of users.

The findings of this research revealed interesting results regarding the challenges in the organizational culture of Afghan universities. Based on the result of the interview, lack of commitment to use HELMS among stakeholders was a major cultural barrier in universities. Evidence revealed that some of the lecturers and members of the university management team were not ready to support the use of HELMS as an alternative to onsite education. The possible explanation for their low commitment can be mentioned as: lack of knowledge on HELMS benefits, low level of HELMS and ICT literacy, their belief toward the low level of perceived usefulness toward HELMS, and lack of detailed policy on HELMS implementation and use. Lack of commitment among stakeholders has even led to resistance to change, which can be expressed as another cultural issue that faced HELMS's success to serious challenges in Afghan universities. In addition, the study revealed that low level of willingness in exchanging expertise, tolerance showed by the head of the department toward the negligence behavior among their lecturers, and lack of respect to the degree of the hierarchy were the other key cultural issues found in the universities. The appropriate justification for the mentioned cultural issues that exist in the universities can be stated as: lack of a detailed policy on HELMS implantation via expertise exchange, replacement of subjective norms with objective decisions, and a sensation of independence from higher rank officials among lecturers and medium-level management of universities. While other literature has just indicated the cultural challenges that exist among the lecturers regarding the use of learning management systems or e-learning in terms of instructor's roles and rules inside the university (Aldowah et al., 2019; Hakimzadeh et al., 2016), cultural challenges in the whole context of the organization were not widely studied and investigated in other literature. Therefore, the result of studying organizational culture revealed unexpected findings in the context of learning management system implementation, especially in Afghanistan.

According to the results, technical issues were mostly system usability barriers that had slowed down the process of using HELMS during a small period, but according to evidence, it has not been the cause to prevent the use or acceptance of HELMS. Therefore, these technical challenges were not identified as preventative issues toward the use of HELMS. Lack of password recovery function was the key issue that faced university administration into trouble during the management of the system. Technical challenges were also a potential barrier found in the literature (De Smet et al., 2016; Taat \& Francis, 2020). 
This research also explored the factors influencing the use of HELMS among students. The result showed that eight major factors groups including infrastructure, economic, university management, ICT and HELMS literacy, performance expectancy, content quality, LMS quality, and lecturers' behavior are found to influence the use of HELMS by students. The findings indicate that unlike many studies in developing countries, the use of learning management systems among students in Afghanistan are highly affected by fundamental influential factors such as infrastructure (internet, electricity, and hardware), economic (the price of internet, and associated cost with hardware), and ICT skill (knowledge of computer, internet, and HELMS). Besides, evidence shows that lack of detailed planning on the use of HELMS during quarantine due to Covid-19 across the country was the basic reason for the unscheduled timeline for use of HELMS. Following researches in the context of developing countries confirm the impact of these basic factors (Aung \& Khaing, 2016; El-Masri \& Tarhini, 2017). This research also confirms the impact of performance expectancy (degree of usefulness, expected outcome, relative advantage), content quality (quality of e-content on the HELMS), LMS quality (quality of HELMS in term of usability), university management (management issues inside university), and lecturers' behavior on the use of learning management systems, which were also found to be proofed by the other pieces of literature (Alariqi et al., 2019; Aung \& Khaing, 2016; El-Masri \& Tarhini, 2017; Shafiei Sarvestani et al., 2019; Shroff et al., 2007). Unlike previous research in the context of Jordan and Saudi Arabia by Almaiah et al., (2020), the impact of security, trust, and privacy was not found to be influential on HELMS use among students due to the lack of knowledge on possible consequence caused by the disclosure of private data.

This study has also investigated the influential factors on the use of HELMS among lecturers. Unlike students, in which their primary concerns were ICT and HELMS literacy, lecturers' level of acceptance was highly affected by their knowledge on e-content development. Lack of necessary skills in e-content development was a major issue concerning their use of HELMS. Besides, lecturers stated that necessary resources for e-content development were not provided. Although HELMS was planned to be used and implemented, MoHE and universities were less concerned to provide resources for e-content development. Dedicated rooms resembling video studios with essential hardware for video recording and editing are mentioned to be the primary needs for content development. Moreover, unlike students which defined learning management systems' quality basically as usability factors, teachers had a more in-depth view of LMS quality defined as usability, availability, accessibility, and functionality of HELMS. Evidence proved that not only the easiness associated with the use of HELMS, but also uptime level, presence of necessary function in HELMS, and accessibility of HELMS across platforms are the influential factors having an impact on acceptance and use of HELMS. The stated findings are confirmed in other pieces of literature in the context of developing countries (Aldowah et al., 2019; Eltahir, 2019; Meriem \& Youssef, 2019; Vershitskaya et al., 2019; Weaver et al., 2008). This study has also resulted in finding the impact of performance expectancy (expected outcome and usefulness of HELMS) on the use of HELMS among lecturers. Low level of knowledge on HELMS, lack of prior experience in using HELMS, and low level of ICT 
and HELMS literacy are the possible explanations for the low level of performance expectancy among lecturers.

According to the diffusion theory expressed by Beal and Bohlen, (1956), technology diffusion into the community requires initiating a process comprised of the awareness stage, interest stage, evaluation stage, trial stage, and finally adoption stage. Based on the stated theory, the success of technology portrayed with full adoption of the service is gained after detailed planning on 1) increasing the level of awareness, 2) enhancing the interest level among individuals, 3) making the individuals evaluate the system, which will then lead to 4) put them in a situation to try the technology. Results obtained showed that lack of belief in the relative advantage and performance expectancy of HELMS indicates the necessity to enhance the awareness of HELMS benefits and use among the users. Thus, as a pre-requisite to the deployment of HELMS, it was expected to conduct awareness programs to inform various stakeholders and enhance their knowledge on HELMS benefits based on detailed policies and guidelines. Other stages of the diffusion process would take place afterward. The choice for incorporating the blended learning method for facilitating the diffusion of E-learning can be a possible way to enhance the awareness and persuade the students in evaluating the HELMS. Previous literature on blended learning found that planned use of blended learning can enhance not only the quality of education, but also the students' and lecturers' desire to adopt online learning (Castro, 2019; Ibrahim \& Nat, 2019; Serrano, DeaAyuela, Gonzalez-Burgos, Serrano-Gil, \& Lalatsa, 2019). Therefore, incorporating blended learning in higher educational institutes will help to pave the way for HELMS adoption by expanding awareness, enhancing the interest level among stakeholders toward HELMS, providing the choice to evaluate the system, making them actually try out the HELMS, and finally reaching full adoption.

On the other hand, reports and statistics from ITU (International Telecommunication Union) show the level of mobile technology use among the population, which is described with an average of 59 percent mobile ownership and 12 percent of the population internet use among the population (ITU, 2019a) (ITU, 2019b). Thus, considering the findings of this research indicating the challenges of users stated as infrastructural (lack of access to ICT technologies, lack of access to electricity and consistent infrastructure), skills (ICT skills, ICT literacy), and economic issues (low purchasing power), development, and implementation of internet service such as HELMS in such a context is challenging. This study provides the support that successful implementation and use of learning management systems highly depend on ICT infrastructure, ICT skills level, and economic status of users in a country.

\section{Recommendations}

The findings and recommendations of this research will be helpful for government officials, public administrators in higher education institutes, academic researchers, HELMS administration committees, E-learning committees in public universities, and other practitioners that use learning management systems. 
- E-learning policy for the universities and higher education institutes should be developed. The policy should contain all relevant components that clearly address issues related to governance, quality, training, implementation plan, rewards, and incentives. Along with this, universities should highly focus on E-learning implementation and use in their strategic plans. Policies should then be communicated to all stakeholders and necessary changes should be reflected as part of policy revision regularly.

- Training and workshops should be conducted for all users and university management with the necessary content for the target users. To enhance the students' knowledge of E-learning and HELMS, E-learning should be integrated into the curriculum by offering a required seminar to enhance the knowledge of students on E-learning and the use of HELMS. While training should be done, knowledge of trainers on HELMS and E-learning, the trainers' attitude toward HELMS, and trainers' communication skills are the key aspects to be considered.

- To facilitate the diffusion of the HELMS in higher education institutes among all stakeholders, MoHE should work on detailed policies and planned strategies for incorporating blended learning into the educational system. Blended learning can help all stakeholders to get involved in using HELMS and continuously evaluate the system, which will then help them to get adopted to the HELMS easily.

- To address issues related to the governance and operation of HELMS inside the university, the policymakers and high-level authorities should work on developing appropriate procedures and guidelines to formalize the tasks inside a framework within which the HELMS should operate. As part of this, the roles and responsibilities of all stakeholders and procedures should clearly be indicated.

- To address the quality aspects of HELMS, guidelines should be defined that include the quality indicators for various aspects of HELMS including teaching quality, e-content quality, and system quality. The quality of e-content and quality of teaching requires continuous monitoring to have a better outcome of teaching and learning.

- The university should provide technical supports for their lecturers, helping them overcome the infrastructure, economic, and content-making challenges. On the other hand, the Government should undertake actionable plans for reducing the high cost of the internet and provision of consistent electricity for people living in both rural and urban areas.

- To overcome negligence and careless behavior among all stakeholders of the HELMS, and to have control over incompetent behavior among stakeholders of the HELMS, punishments, and rewards should be part of organizations' reactions and should be followed seriously.

- The HELMS designers and administrators should follow user-centric design rules and guidelines to enhance usability, reliability, availability, and accessibility of the system based on the users' needs for all relevant stakeholders.

- The MoHE should provide support and incentives for lecturers to conduct researches on E-learning from a variety of aspects to investigate the challenges, opportunities, trends, status, and factors influencing the use of E-learning among all stakeholders at both public and private universities. 


\section{Conclusion}

This research is the first comprehensive investigation of the potential challenges of HELMS from both managerial and HELMS users' perspectives through a qualitative approach in the context of Afghanistan. This research used interviews of both individuals and focus groups as the medium of data collection. Qualitative thematic analysis was used for the analysis of qualitative data. It provided an in-depth study of challenges from different managerial aspects including policy, organizational culture, technical, governance model, skills, and quality of service. The result indicates that a lack of policy is the most important area of challenge that had a high impact on the success of HELMS. Additionally, lack of policy documents caused other major areas of the challenge such as skill, quality of service, governance model to be affected. Findings reveal that technical issues were not recognized to have a high impact on the acceptance and success of HELMS. Yet, it is a potential challenge domain to be considered for the further success of HELMS. The research also found out that challenges that exist in the organizational culture of Afghan universities have a serious impact on the success and failure of HELMS in the universities. Consequently, this paper highlighted the most significant factors influencing the use of HELMS among students and lecturers. According to them, factors representing infrastructure, economic, university management, ICT and HELMS literacy, performance expectancy, content quality have a serious impact on acceptance and use of HELMS. However, from the lecturers' point of view, they are more concerned about the factors indicating the skills, infrastructure, and LMS quality aspects. Considering the results of this study at explaining the challenges of using learning management systems from a managerial perspective and understanding the factor influencing the use of HELMS among both students and lecturers, views and criticism expressed in this study helped us explaining the problem widely by studying the problem from various perspectives and added to the existing knowledge on challenges in use and adoption of learning management systems in the context of Afghanistan and other countries with a similar situation. In addition, this study presented practical solutions to overcome the challenges that stakeholders including the university management, students, and lecturers confront in the adoption and use of HELMS.

\section{Limitation and future research direction}

This study is limited in a number of ways. First, this study is limited in its scope, which is studying the challenges of using HELMS among its stakeholders in four universities; the result gathered may not be applied in other contexts. Besides, this study has used a qualitative approach for the analysis of challenges which has its own limitation due to the small sample size. Therefore, the results may not be generalized although efforts have been taken to reduce small sample size errors by collecting interviewees from various backgrounds and demographics. Future research may be conducted on the development of a conceptual model validated using a survey representing the factors affecting the use or attitude of both lecturers and students 
toward HELMS. The research will help us to have a confirmatory study of providing statistically supported significant results that can be generalized and give us detailed information about the critical factors that have an impact on the user behavior of HELMS. Moreover, future research can extend the context of the study and include more universities, including the private universities in their research for giving us a more generalized insight of HELMS challenges in the context of Afghanistan or even do the comparison on influential factors among public and private universities.

Authors' contributions All authors contributed to the study conception and design. Material preparation, data collection, and analysis were performed by Mustafa Kamel Mohammadi, Dr. Abdul Azizi Mohibbi, and Dr. Mohammad Hadi Hedayati. The first draft of the manuscript was written by the corresponding author, followed by comments and revisions by other authors. All authors read and approved the final manuscript.

The authors state that none of the involved authors in conducting this research has received any funding for conducting the study. In addition, the authors certify that there are not any financial /personal beliefs or interests that could affect the objectivity of this research or their judgments.

\section{References}

Al-araibi, A. A. M., Mahrin M. N. Bin, \& Yusoff, R. C. M. (2019). Technological aspect factors of E-learning readiness in higher education institutions: Delphi technique. Education and Information Technologies, 24(1), 567-590. https://doi.org/10.1007/s10639-018-9780-9.

Al Musawi, A. S., \& Abdelraheem, A. Y. (2004). E-learning at Sultan Qaboos University: status and future Ali Sharaf Al Musawi and Ahmed YousifAbdelraheem. British Journal of Educational Technology, 35(3), 363-367. https://doi.org/10.1111/j.0007-1013.2004.00394.x.

Alaeddini, M., \& Kardan, A. A. (2010). E-Learning Governance - Towards an applicable framework A . Key E-Iearning Decisions. In 2010 2nd International Conference on Education Technology and Computer (ICETC) (pp. 529-533). https://doi.org/978-1-4244-6370-11\$26.00.

Alariqi, A. A., Najafi, M., Abdulrab, M., Murray, C., \& Slimanzai, H. (2019). Factors affecting e-learning effectiveness in a higher learning institution in Afghanistan. ACM International Conference Proceeding Series, 176-181. https://doi.org/10.1145/3369255.3372275.

Aldowah, H., Al-Samarraie, H., \& Ghazal, S. (2019). How course, contextual, and technological challenges are associated with instructors' individual challenges to successfully implement e-Learning: a developing country perspective. IEEE Access, 7, 48792-48806. https://doi.org/10.1109/ACCESS. 2019.2910148.

Almaiah, M. A., Al-Khasawneh, A., \& Althunibat, A. (2020). Exploring the critical challenges and factors influencing the E-learning system usage during COVID-19 pandemic. Education and Information Technologies, 25(6), 5261-5280. https://doi.org/10.1007/s10639-020-10219-y.

Almaiah, M. A., \& Al Mulhem, A. (2018). A conceptual framework for determining the success factors of E-learning system implementation using Delphi technique. Journal of Theoretical and Applied Information Technology, 96(17), 5962-5976.

Almaiah, M., \& Alyoussef, I. Y. (2019). Analysis of the effect of course design, course content support, course assessment and instructor characteristics on the actual use of e-Learning system. IEEE Access, 7, 171907-171922. https://doi.org/10.1109/ACCESS.2019.2956349.

Alqahtani, A. Y., \& Rajkhan, A. A. (2020). E-learning critical success factors during the covid-19 pandemic: A comprehensive analysis of e-learning managerial perspectives. Education Sciences, 10(9), 1-16. https://doi.org/10.3390/educsci10090216.

Ameen, N., Willis, R., Abdullah, M. N., \& Shah, M. (2019). Higher education in Iraq : A student perspective. British Journal of Educational Technology, 50(3), 1434-1446. https://doi.org/10.1111/ bjet. 12651 . 
Atan, H., Embi, M. A., \& Hussin, S. (2011). e-Learning policy in Malaysian higher education institutions. e-learning in Malaysian higher education institutions: Status, trends, \& challenges. Ministry of Higher Education of Malaysia.

Aung, T. N., \& Khaing, S. S. (2016). Challenges of implementing e-learning in developing countries: A review. In Advances in intelligent systems and computing (Vol. 388, pp. 405-411). https://doi.org/ 10.1007/978-3-319-23207-2_41.

Bamyan University. (2020). E-learning status in Bamyan University, Bamyan City, Afghanistan. Internal Report of Bamyan University: unpublished.

Beal, G. M., \& Bohlen, J. M. (1956). Diffusion process. No. 761-2016-51585, pp. 111-121.

Beebe, M. (2010). E-learning in Afghanistan. Retrieved from https://linc.mit.edu/linc2010/proceedings/ session1Beebe.pdf. Accessed 21 Aug 2020.

Castro, R. (2019). Blended learning in higher education: Trends and capabilities. Education and Information Technologies, 24(4), 2523-2546. https://doi.org/10.1007/s10639-019-09886-3.

Chang, S. C., \& Lee, M. S. (2007). A study on relationship among leadership, organizational culture, the operation of learning organization and employees' job satisfaction. Learning Organization, 14(2), 155-185. https://doi.org/10.1108/09696470710727014.

De Smet, C., Valcke, M., Schellens, T., De Wever, B., \& Vanderlinde, R. (2016). A qualitative study on learning and teaching with learning paths in a learning management system. Journal of Social Science Education, 15(1), 27-37.

DeLone, W. H., \& McLean, E. R. (1992). Information systems success: The quest for the dependent variable. Information Systems Research, 3(1), 60-95. https://doi.org/10.1287/isre.3.1.60.

Dhawan, S. (2020). Online Learning: A Panacea in the Time of COVID-19 Crisis. Journal of Educational Technology Systems, 41(1), 5-22. https://doi.org/10.1177/0047239520934018.

El-Masri, M., \& Tarhini, A. (2017). Factors affecting the adoption of e-learning systems in Qatar and USA: Extending the Unified Theory of Acceptance and Use of Technology 2 (UTAUT2). Educational Technology Research and Development, 65(3), 743-763. https://doi.org/10.1007/ s11423-016-9508-8.

Eltahir, M. E. (2019). E-Learning in developing countries: Is it a Panacea? A case study of Sudan. IEEE Access, 7.https://doi.org/10.1109/ACCESS.2019.2930411.

Hakimzadeh, R., Dehghani, M., Javadipour, M., \& Malekipour, A. (2016). Investigating the challenges of the effective implementation of E-learning courses at Payame Noor University of Dehloran. Interdisciplinary Journal of Virtual Learning in Medical Sciences, 7(2), 0-5. https://doi.org/10.5812/ ijvlms. 12153.

Hofstede, G. H., Hofstede, G. J., \& Minkov, M. (2005). Cultures and organizations: Software of the Mind. Mcgraw-hill New York (Vol. 2). https://doi.org/10.1007/s11569-007-0005-8.

Ibrahim, M. M., \& Nat, M. (2019). Blended learning motivation model for instructors in higher education institutions. International Journal of Educational Technology in Higher Education, 16(1). https:// doi.org/10.1186/s41239-019-0145-2.

Ismail, M., Embi, M. A., \& Nordin, N. M. (2011). Quality assurance and e-learning future plans. In M. A. Embi (Ed.), e-learning in Malaysian higher education institutions: Status, trends, \& challenges.

ITU. (2019a). Individuals using the Internet (\% of population) - Afghanistan. Retrieved from https://data. worldbank.org/indicator/IT.NET.USER.ZS? end=2019\&locations =AF\&start=2002\&view $=$ chart. Accessed 11 Sept 2020.

ITU. (2019b). Mobile cellular subscriptions (per 100 people) - Afghanistan. Retrieved from https://data. worldbank.org/indicator/IT.CEL.SETS.P2?view=chart\&locations=AF. Accessed 11 Sept 2020.

Jamal, H., \& Shanaah, A. (2011). The role of learning management systems in educational environments : An exploratory case study, master dissertation, school of computer science, phisics and mathematics, Linnaeus University, Växjö campus, Sweden, 57. Retrieved from http://www.diva-portal.org/ smash/get/diva2:435519/FULLTEXT01.pdf. Accessed 20 Oct 2020.

Kamba, M. A. (2009). Problems, challenges and benefits of implementing e-learning in Nigerian universities: An empirical study. International Journal of Emerging Technologies in Learning, 4(1), 66-69. https://doi.org/10.3991/ijet.v4i1.653.

Kaplan, B., \& Maxwell, J. A. (2006). Qualitative research methods for evaluating computer information systems. In Evaluating the organizational impact of healthcare information systems (pp. 30-55). Springer-Verlag. https://doi.org/10.1007/0-387-30329-4_2

Lau, P. Y. Y., McLean, G. N., Hsu, Y. C., \& Lien, B. Y. H. (2017). Learning organization, organizational culture, and affective commitment in Malaysia: A person-organization fit theory. Human Resource Development International, 20(2), 159-179. https://doi.org/10.1080/13678868.2016.1246306. 
Leacock, T. (2005). Building a sustainable e-learning development culture. Learning Organization, 12(4), 355-367. https://doi.org/10.1108/09696470510599136.

Leavy, P. (2017). Research design: quantitative, qualitative, mixed Methods, arts-based, and communitybased participatory research approaches. The Guilford Press. https://doi.org/10.1177/1558689817 751775.

Lin, C. Y., Huang, C. K., \& Zhang, H. (2019). Enhancing employee job satisfaction via E-learning: The mediating role of an organizational learning culture. International Journal of Human-Computer Interaction, 35(7), 584-595. https://doi.org/10.1080/10447318.2018.1480694.

Mailizar, Almanthari, A., Maulina, S., \& Bruce, S. (2020). Secondary school mathematics teachers' views on e-learning implementation barriers during the COVID-19 pandemic: The case of Indonesia. Eurasia Journal of Mathematics, Science and Technology Education, 16(7). https://doi.org/10. 29333/EJMSTE/8240

Malterud, K., Siersma, V. D., \& Guassora, A. D. (2016). Sample size in qualitative interview studies. Qualitative Health Research, 26(13), 1753-1760. https://doi.org/10.1177/1049732315617444.

Marshall, S. (2012). E-learning and higher education: Understanding and supporting organisational change in New Zealand. Journal of Open, Flexible and Distance Learning, 16(1), 141-155. Retrieved from https://journals.akoaotearoa.ac.nz/index.php/JOFDL/article/viewFile/96/66. Accessed 10 Nov 2020.

Meriem, B., \& Youssef, A. M. (2019). Exploratory analysis of factors influencing e-learning adoption by higher education teachers : Case study: Abdelmalek Essaâdi University- Morocco. Education and Information Technologies, 25(3), 2297-2319. https://doi.org/10.1007/ s10639-019-10075-5.

Mohamed Amin Embi. (2011). e-Learning in Malaysian higher education institutions: Status trends \& challenges. (M. A. Embi, Ed.), Department of Higher Education, Ministry of Higher Education. Department of Higher Education Ministry of Higher Education of Malaysia. https://doi.org/10. 1017/CBO9781107415324.004

Pham, L., Limbu, Y. B., Bui, T. K., Nguyen, H. T., \& Pham, H. T. (2019). Does e-learning service quality influence e-learning student satisfaction and loyalty? Evidence from Vietnam. International Journal of Educational Technology in Higher Education, 16(7). https://doi.org/10.1186/ s41239-019-0136-3

Quick, J., \& Hall, S. (2015). Part Two: Qualitative Research. Journal of Perioperative Practice, 25(7-8), 129-133. https://doi.org/10.1177/1750458915025007-803.

Rosacker, K. M., \& Olson, D. L. (2008). Public sector information system critical success factors. Transforming Government: People, Process and Policy, 2(1), 60-70. https://doi.org/10.1108/1750616081 0862955 .

Rosenberg, M. J., \& Foshay, R. (2002). E-learning: Strategies for delivering knowledge in the digital age. Performance Improvement, 41(5), 50-51. https://doi.org/10.1002/pfi.4140410512.

Roumell, E. A., \& Salajan, F. D. (2016). The evolution of U.S. e-learning policy: A content analysis of the national education technology plans. Educational Policy, 30(2), 365-397. https://doi.org/10. $1177 / 0895904814550070$.

Sabherwal, R., Jeyaraj, A., \& Chowa, C. (2006). Information system success: Individual and organizational determinants. Management Science, 52(12), 1849-1864. https://doi.org/10.1287/mnsc.1060. 0583 .

Serrano, D. R., Dea-Ayuela, M. A., Gonzalez-Burgos, E., Serrano-Gil, A., \& Lalatsa, A. (2019). Technology-enhanced learning in higher education: How to enhance student engagement through blended learning. European Journal of Education, 54(2), 273-286. https://doi.org/10.1111/ejed.12330.

Shafiei Sarvestani, M., Mohammadi, M., Afshin, J., Raeisy, L., \& Sarvestani, S. M. (2019). Students' Experiences of E-Learning Challenges; a Phenomenological Study. Interdisciplinary Journal of Virtual Learning in Medical Sciences, 10(3), 1-10.

Shraim, K., \& Khlaif, Z. (2010). An e-learning approach to secondary education in Palestine: Opportunities and challenges. Information Technology for Development, 16(3), 159-173. https://doi.org/10. 1080/02681102.2010.501782.

Shroff, R. H., Vogel, D. R., Coombes, J., \& Lee, F. (2007). Student e-Learning intrinsic motivation: A qualitative analysis. Communications of the Association for Information Systems, 19(March). https:// doi.org/10.17705/1 cais.01912

Snoussi, T. (2019). Learning management system in education: Opportunities and challenges. International Journal of Innovative Technology and Exploring Engineering, 8(12S), 664-667. https://doi. org/10.35940/ijitee.11161.10812s19 
Sokout, H., \& Usagawa, T. (2018). Analyzing the current situation of E-learning at Kabul Polytechnic University. In Proceedings of the 2nd International Conference on Education and Multimedia Technology (pp. 49-53). ACM. https://doi.org/10.1145/3206129.3239428

Sulaiman, A. H., Embi, M. A., \& Hamat, A. (2011). e-Content development in Malaysian higher education institutions. In M. A. Embi (Ed.), e-Learning in Malaysian Higher Education Institutions: Status, Trends, \& Challenges. Ministry of Higher Education of Malaysia.

Taat, M. S., \& Francis, A. (2020). Factors influencing th e students' acceptance of E-Learning at teacher education institute : An exploratory study in Malaysia. International Journal of Higher Education, 9(1). https://doi.org/10.5430/ijhe.v9n1p133

Thongsri, N., Shen, L., \& Bao, Y. (2019). Investigating academic major differences in perception of computer self-efficacy and intention toward E-learning adoption in China. Innovations in Education and Teaching International, 1-13. https://doi.org/10.1080/14703297.2019.1585904

Tracy, S. J. (2013). Qualitative research methods: Collecting evidence, crafting analysis, communicating impact. (S. J. Tracy, Ed.), Blackwell's publishing (First Edit). Blackwell Publishing Ltd. https://doi. org/10.5613/rzs.43.1.6.

Vaismoradi, M., Jones, J., Turunen, H., \& Snelgrove, S. (2016). Theme development in qualitative content analysis and thematic analysis. Journal of Nursing Education and Practice, 6(5). https://doi.org/ 10.5430/jnep.v6n5p100

Vaismoradi, M., Turunen, H., \& Bondas, T. (2013). Content analysis and thematic analysis: Implications for conducting a qualitative descriptive study. Nursing and Health Sciences, 15(3), 398-405. https:// doi.org/10.1111/nhs.12048.

Vershitskaya, E. R., Mikhaylova, A. V, \& Gilmanshina, S. I. (2019). Present-day management of universities in Russia : Prospects and challenges of e-learning. Education and Information Technologies, 25(1). https://doi.org/10.1007/s10639-019-09978-0

Wahab, Z. A., Embi, M. A., \& Nordin, N. M. (2011). e-Learning governance in Malaysian higher education institutions. (M. A. Embi, Ed.), e-Learning in Malaysian Higher Education Institutions: Status, Trends, \& Challenges. Ministry of Higher Education of Malaysia.

Weaver, D., Spratt, C., \& Nair, C. S. (2008). Academic and student use of a learning management system: Implications for quality. Australasian Journal of Educational Technology, 24(1), 30-41. https://doi. org/10.14742/ajet.1228

Weil, P., \& Ross, J. (2004). IT Governance - How Top Performers Manage IT Decision Rights for Superior Results. (1sth ed.). Harvard Business School Press.

WHO. (2020). Coronavirus (Covid-19) events as they happen. Retrieved December 10, 2020, from https://www.who.int/emergencies/diseases/novel-coronavirus-2019/events-as-they-happen

Publisher's note Springer Nature remains neutral with regard to jurisdictional claims in published maps and institutional affiliations.

\section{Authors and Affiliations}

\section{Mustafa Kamel Mohammadi ${ }^{1}$ (D) Abdul Aziz Mohibbi ${ }^{2}$. Mohammad Hadi Hedayati ${ }^{3}$}

Abdul Aziz Mohibbi

aziz.mohibbi@bu.edu.af

Mohammad Hadi Hedayati

hdhedayati@gmail.com

1 Department of Computer Education, Education Faculty, Bamyan University, Bamyan, Afghanistan

2 Agriculture Faculty, Kabul University, Kabul, Afghanistan

3 Computer Science Faculty, Kabul University, Kabul, Afghanistan 